\title{
Psychometric Properties and Validation of the 9-Item Social Media Scale Among Pre-University Students in Nigeria
}

\author{
T Afe, O Ogunsemi, A Ayotunde, A Olufunke, B Osalusi, B Afe
}

\begin{abstract}
Objective: To validate the Social Media Disorder scale in Nigerian adolescents by determining its unidimensional structure, reliability, sensitivity, specificity, and criterion validity.

Methods: A total of 516 and 1213 pre-university students in two universities were randomly recruited and assessed using the 9-item Social Media Scale and the 12-item General Health Questionnaire (in the second survey only).

Results: $46.3 \%$ and $56.3 \%$ of respondents in the first and second surveys met the criteria for social media disorder, respectively. Factor loading of items on the latent factor (addiction) was moderate. The model yielded a fairly acceptable fit in both samples. The averaged measure for intra-class correlation was acceptable (0.612). The internal consistency (Cronbach's alpha) was good ( 0.713 for sample 1 and 0.724 for sample 2). The test-retest reliability among the 113 respondents was good $(\mathrm{r}=0.696, \mathrm{p}<0.001)$. The item-total correlations were all significant. Sensitivity of each item ranged from $67.7 \%$ (tolerance) to $91.3 \%$ (escape); specificity of each item ranged from $41.2 \%$ (escape) to $87.6 \%$ (displacement). For criterion validity, the total Social Media Disorder scale score correlated with General Health Questionnaire items that assess self-esteem, depression, and mood, as well as the total score.

Conclusion: The 9-item Social Media Disorder scale is acceptable for screening social media disorder in pre-university students in Nigeria. The high prevalence of social media disorder should be of concern to counsellors, teachers, and mental health practitioners. Strategies for public health education on social media use are needed in Nigeria.
\end{abstract}

Key words: Behavior, addictive; Psychometrics; Social Media; Students; Validation study

Taiwo Afe, Department of Medicine, Olabisi Onabanjo University, Ogun State, Nigeria

Olawale Ogunsemi, Department of Medicine, Olabisi Onabanjo University, Ogun State, Nigeria

Ale Ayotunde, Department of Medicine, Olabisi Onabanjo University, Ogun State, Nigeria

Adeleye Olufunke, Department of Medicine, Olabisi Onabanjo University, Ogun State, Nigeria

Bamidele Osalusi, Department of Medicine, Olabisi Onabanjo University, Ogun State, Nigeria

Blessing Afe, Citi-point Chambers, Lagos, Nigeria

Address for correspondence: Dr Taiwo Afe, Department of Medicine, Olabisi Onabanjo University, Ogun State, Nigeria.

Email:afeet23@yahoo.co.uk

Submitted: 1 July 2019; Accepted: 22 June 2020

\section{Introduction}

Social media is a means of communication in modern life. ${ }^{1}$ The widespread availability and instantaneous communication are attractive to many youths. The opportunity to connect to a worldwide community fuels its appeal to all kind of users. ${ }^{2}$ It has become a preferred tool for social networking across all age groups. ${ }^{3}$

Adolescents and young adults constitute a larger percentage of social media users. ${ }^{4}$ In the United States, $88 \%$ of social media users were adolescents of age 18 to 29 years. ${ }^{3}$ In Nigeria in 2017, social media (Facebook) users reached 17 million, with most being adolescents and young adults. ${ }^{5}$ Nigeria has the highest number of social media users in Africa.

Addictive behaviours among frequent social media users are similar to those seen in substance users and internet game players ${ }^{2,6}$ and are known as social media disorder. ${ }^{7,8}$ However, the concept and criteria for diagnosis remain controversial among researchers. The criteria of social media disorder are adapted from those of internet gaming disorder in DSM-5. ${ }^{9}$ The diagnosis of internet gaming disorder is based on criteria for substance dependence and pathological gambling, which include preoccupation, tolerance, withdrawal, deception, conflict, displacement escape, persistence of use, and problems/conflict. ${ }^{10-12}$

The 9-item Social Media Disorder scale is a generic instrument for all social platforms and is based on the DSM-5 criteria for internet gaming disorder. It has good psychometric properties and is valid for assessing social media disorder. ${ }^{11}$ The aim of this study was to validate the Social Media Disorder scale in Nigerian adolescents by determining its unidimensional structure, reliability, sensitivity, specificity, and criterion validity. 


\section{Materials and Methods}

This study was approved by the institutional review board of the Olabisi Onabanjo University (OOUTH/ HREC/267/2019). Pre-university students were purposely recruited from the Olabisi Onabanjo University (a state university) and a federal university in southwest Nigeria. Informed consent was obtained from each participant. Anonymity was assured. The inclusion criteria were regular users for $\geq 1$ year of at least one social media account (eg, Facebook, Twitter, WhatsApp, Snapchat, Instagram).

A pilot study was conducted to correct unclear wordings and statements in the Social Media Disorder scale in 27 female and 24 male first-year students (age 17 to 20 years) who were regular users of social media invited through various student group Whatsapp platforms.

In the first survey, students attending preparatory/ diploma classes for university entrance in the state university were randomly recruited between February and July 2017. $26(0.05 \%)$ students (mean age, $19.17 \pm$ 1.27 years) declined further participation owing to not use of any social media any longer. $19(6.03 \%)$ respondents omitted vital sociodemographic data such as age and sex. A total of $516(92.0 \%)$ participants (271 women and 245 men) [mean age, $19.33 \pm 1.89$ years] were suitable for analysis. The mean age of those who declined and those who participated was comparable $(\mathrm{t}=2.86, \mathrm{p}=0.99)$. $230(41 \%)$ of them (mean age, $19.25 \pm 1.21$ years) gave their contact details (phone numbers and emails) for a retest 4 weeks later. The mean age of those who participated in the re-test and those who did not was comparable $(t=2.07$, $\mathrm{p}=0.98)$. Only $113(49.1 \%)$ of participants (mean age, 19.12 years) completed the retest. The mean age of those who completed the retest and those who failed to complete were comparable $(\mathrm{t}=0.64, \mathrm{p}=0.74)$.

In the second survey, students attending preparatory university/diploma classes of the federal university were randomly recruited using registration numbers between March 2017 and June 2018. Postgraduate students and nonacademic staff members helped in the recruitment. A total of 1213 participants ( 659 women and 554 men) [mean age, $17.98 \pm 1.60$ years] were included.

The 9-item Social Media Disorder scale was used to screen for social media disorder. It has similar psychometric properties to the 27-item version based on the DSM-5 criteria for internet gaming disorder. ${ }^{11}$ It is easy to administer in large population studies. The 9 items are: preoccupation (have you regularly found that you can't think of anything else but the moment that you will be able to use social media again?), tolerance (regularly felt dissatisfied because you wanted to spend more time on social media?), withdrawal (often felt bad when you could not use social media?), persistence (tried to spend less time on social media, but failed?), displacement (regularly neglected other activities (eg, hobbies, sport) because you wanted to use social media?), problems (regularly had arguments with others because of your social media use?), deception (regularly lied to your parents or friends about the amount of time you spend on social media?), escape (often used social media to escape from negative feelings?), and conflict (had serious conflict with your parents, friends, brother(s) or sister(s) because of your social media use?). Responses are dichotomised as yes $=1$ and no $=0$; the cut-off of $\geq 5$ positive responses is indicative of social media disorder. ${ }^{11}$

The 12-item General Health Questionnaire (GHQ) ${ }^{13}$ was used to screen for psychological morbidity among $<200$ students in the second survey. It is easy to administer and has been validated in Nigeria. ${ }^{14-18}$ It contains an equal number of positively and negatively worded questions ${ }^{19}$ on a Likert scale of 0 to $3 .{ }^{15}$ There are no validated instruments in Nigeria for social media addiction. We hypothesised that those positive for social media addiction would score high on psychological morbidity measured by GHQ.

Statistical analysis was performed using SPSS (Windows version 21; IBM Corp, Armonk [NY], US). Internal consistency of the 9-item Social Media Disorder scale was assessed using Cronbach's alpha. Intra-class correlations were assessed using a two-way mixed effect model.Test-retest reliability and item-total score correlations were assessed using Pearson Correlation. The weighted least squares mean- and variance-adjusted estimation was used to test the unidimensionality of the Social Media Disorder scale in the confirmatory factor analysis using the M Plus software (version 6.12), which is most appropriate for dichotomous and categorical variables. ${ }^{20}$ Model fit was also tested using the Chi-square goodness of fit, root mean square error of approximation (RMSEA), comparative fit index (CFI) / Tucker Lewis Index (TLI), ${ }^{21}$ and weighted root mean square residual (WRMR) ${ }^{20} \mathrm{Chi}$-square goodness of fit is not a stable measure of fitness as it is subject to the sample size. ${ }^{22}$ RMSEA is based on the covariance's matrix and estimates differences between the hypothesised model and the model under observation when they share related components. ${ }^{23}$ The RMSEA cut-off is usually at 0.05 , and $<0.08$ is considered good fit. ${ }^{24,25}$ The CFI/TFI estimate differences between the hypothesised model and the observed model when they do not share related components. The TFI penalises lack of parsimony in the null model. ${ }^{24} \mathrm{~A}$ CFI/TFI of $>0.90$ is indicative of good fit, ${ }^{21}$ as is a WRMR of $<1.0 .^{20}$ The prevalence of social media disorder was determined using a cut-off of $\geq 5$ positive responses in the Social Media Disorder scale. Sensitivity of each item was determined by the proportion of participants with social media disorder who answered 'yes'. Specificity of each item was determined by the proportion of participants without social media disorder who answered 'no'. For criterion validity, correlations of the Social Media Disorder scale total score with GHQ total score and subscores were assessed in $<200$ students in the second survey.

\section{Results}

A total of 930 female and 799 male students aged 16 to 20 years responded. The mean time to complete the 9-item 
Social Media Disorder scale was 2 minutes 45 seconds. The mean GHQ score was $9.73 \pm 6.57 .46 .3 \%$ and $56.3 \%$ of respondents in the first and second surveys met the criteria for social media disorder, respectively (Table 1).

Factor loading of items on the latent factor (addiction)

Table 1. Sociodemographics of respondents

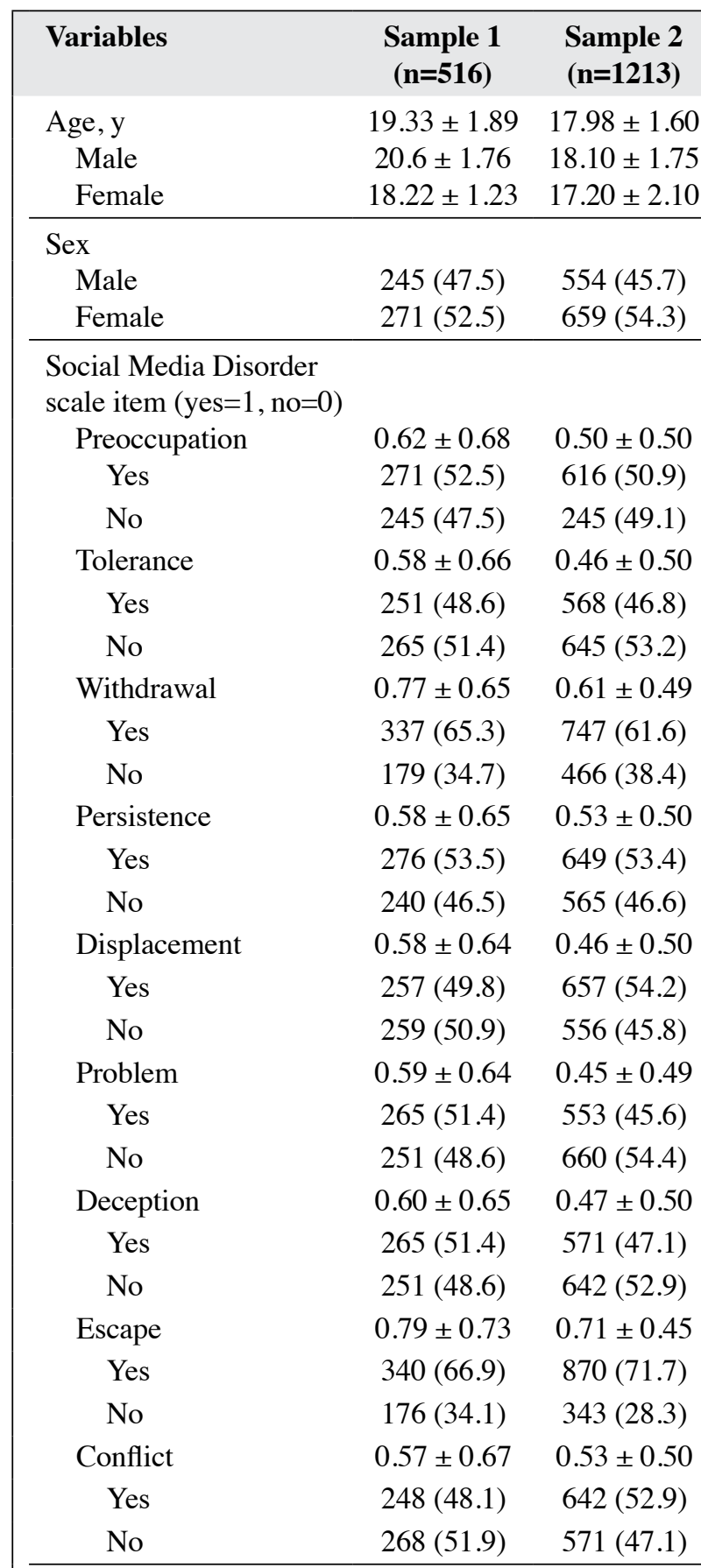

Social Media Disorder

scale score

$\begin{array}{lll}\text { Not addicted }(\leq 4) & 277(53.7) & 560(46.2) \\ \text { Addicted }(\geq 5) & 289(46.3) & 653(53.8)\end{array}$

Data are presented as mean \pm standard deviation or no. (\%) of respondents was moderate (Table 2). Five items in sample 1 had factor loading of $>0.5$ : withdrawal, persistence, displacement, problem, and escape, whereas all items in sample 2 had factor loading of $>0.5$. The model yielded a fairly acceptable fit in both sample $1\left(\chi^{2}=86.807, \mathrm{p}=0.0001\right.$, RMSEA $=0.066$, $\mathrm{CFI}=0.956, \mathrm{TLI}=0.941, \mathrm{WRMR}=1.005]$ and sample 2 $\left(\chi^{2}=146.081, \mathrm{p}=0.0001, \mathrm{RMSEA}=0.06, \mathrm{CFI}=0.950\right.$, TLI $=0.930$, WRMR $=1.550)$.

The averaged measure for intra-class correlation was acceptable $(0.612,95 \%$ confidence interval $=0.343$ 0.967). The internal consistency (Cronbach's alpha) was good ( 0.713 for sample 1 and 0.724 for sample 2$)$. The test-retest reliability among the 113 respondents was good $(\mathrm{r}=0.696, \mathrm{p}<0.001)$. The item-total correlations ranged from 0.471 (tolerance) to 0.630 (persistence) in sample 1 and from 0.495 (escape) to 0.675 (displacement) in sample 2 ; all correlations were significant at $\mathrm{p}<0.05$ (Table 3 ). Sensitivity of each item ranged from $67.7 \%$ (tolerance) to

Table 2. Factor loading of items on the latent factor (addiction) in the Social Media Disorder scale

\begin{tabular}{|lcc|}
\hline \multirow{2}{*}{ Item } & \multicolumn{2}{c|}{ Factor loading } \\
\cline { 2 - 3 } Preoccupation & Sample 1 & Sample 2 \\
\hline Tolerance & 0.461 & 0.604 \\
\hline Withdrawal & 0.456 & 0.576 \\
\hline Persistence & 0.624 & 0.539 \\
\hline Displacement & 0.599 & 0.550 \\
\hline Problem & 0.750 & 0.777 \\
\hline Deception & 0.502 & 0.656 \\
\hline Escape & 0.486 & 0.532 \\
\hline Conflict & 0.588 & 0.522 \\
\hline
\end{tabular}

Table 3. Item-total correlations of the Social Media Disorder scale

\begin{tabular}{|lcc|}
\hline \multirow{2}{*}{ Item } & \multicolumn{2}{c|}{$\begin{array}{c}\text { Correlation with Social Media } \\
\text { Disorder scale total score }(\boldsymbol{r})\end{array}$} \\
\cline { 2 - 3 } & Sample 1 & Sample 2 \\
Preoccupation & $0.558(\mathrm{p}<0.05)$ & $0.571(\mathrm{p}<0.05)$ \\
\hline Tolerance & $0.471(\mathrm{p}<0.05)$ & $0.509(\mathrm{p}<0.05)$ \\
\hline Withdrawal & $0.502(\mathrm{p}<0.05)$ & $0.528(\mathrm{p}<0.05)$ \\
\hline Persistence & $0.630(\mathrm{p}<0.01)$ & $0.560(\mathrm{p}<0.05)$ \\
\hline Displacement & $0.577(\mathrm{p}<0.05)$ & $0.675(\mathrm{p}<0.05)$ \\
\hline Problem & $0.623(\mathrm{p}<0.05)$ & $0.556(\mathrm{p}<0.05)$ \\
\hline Deception & $0.623(\mathrm{p}<0.05)$ & $0.567(\mathrm{p}<0.05)$ \\
\hline Escape & $0.575(\mathrm{p}<0.05)$ & $0.495(\mathrm{p}<0.05)$ \\
\hline Conflict & $0.575(\mathrm{p}<0.05)$ & $0.523(\mathrm{p}<0.05)$ \\
\hline
\end{tabular}


91.3\% (escape); specificity of each item ranged from $41.2 \%$ (escape) to $87.6 \%$ (displacement). [Table 4].

For criterion validity, among $<200$ students in the second survey, the Social Media Disorder scale total score correlated with GHQ items that assess confidence / self esteem (items 4, 5, 10) and depression / mood (items 6, 7, 8, 11,12 ), as well as the total GHQ score (Table 5).

\section{Discussion}

In the present study, the mean age of samples 1 and 2 was

Table 4. Sensitivity and specificity of the Social Media Disorder scale

\begin{tabular}{|lccccc|}
\hline \multirow{2}{*}{ Item } & \multicolumn{2}{c}{ Sample 1 } & & \multicolumn{2}{c|}{ Sample 2 } \\
\cline { 2 - 3 } \cline { 6 - 6 } & $\begin{array}{c}\text { Sensi- } \\
\text { tivity }\end{array}$ & $\begin{array}{c}\text { Speci- } \\
\text { ficity }\end{array}$ & & $\begin{array}{c}\text { Sensi- } \\
\text { tivity }\end{array}$ & $\begin{array}{c}\text { Speci- } \\
\text { ficity }\end{array}$ \\
Preoccupation & 0.729 & 0.742 & & 0.730 & 0.748 \\
\hline Tolerance & 0.687 & 0.797 & & 0.677 & 0.775 \\
\hline Withdrawal & 0.764 & 0.632 & & 0.807 & 0.607 \\
\hline Persistence & 0.731 & 0.687 & & 0.740 & 0.705 \\
\hline Displacement & 0.710 & 0.876 & & 0.741 & 0.871 \\
\hline Problem & 0.888 & 0.845 & & 0.683 & 0.809 \\
\hline Deception & 0.883 & 0.811 & & 0.683 & 0.777 \\
\hline Escape & 0.913 & 0.412 & & 0.873 & 0.464 \\
\hline Conflict & 0.830 & 0.657 & & 0.758 & 0.738 \\
\hline
\end{tabular}

19.33 and 17.98 years, respectively, which are older than that of respondents in the development of the original scale (14.36 years). ${ }^{11}$ The differences were due to a deliberate effort to sample active users of social media platforms in Nigeria who usually start using the platforms in late adolescence. 5 The number of females was more in both samples. This may be due to response bias, as females are more willing to participate and complete questionnaires. The prevalence of social media disorder was $46.3 \%$ in sample 1 and $56.3 \%$ in sample 2; the prevalence was higher than that in the sample of the original scale. ${ }^{11}$ The differences may be due to differences in the age and location of respondents. Younger students living in urban areas are more likely to own smartphones or need to socialise or have more freedom from parental supervision.

The factor loadings of the items on the latent factor were moderate in both samples. Three of the fit indices (CFI, TFI, RMSEA) showed acceptable fit. Nonetheless, the fit indices in the present study were much lower than those reported in the original scale. ${ }^{11}$ The low fit indices may indicate that the scale may not fully capture the dimensions of social media disorder among older adolescents in Nigeria. The internal consistency was good in both samples (Cronbach's alpha of $>7$ ), consistent with that reported in other studies. ${ }^{2,7}$ The intra-class correlation was acceptable and similar to that reported in the original scale. ${ }^{11}$ The test-retest reliability was good ( $\mathrm{r}=0.696)$. All item-total correlations were significant. Sensitivity of each item was fair to good and specificity of each item was weak to good. For criterion validity, among $<200$ students in the second survey, the Social Media Disorder scale total score correlated with GHQ items that assess self-esteem, depression, and mood, as well as the

Table 5. Correlations between the Social Media Disorder scale total score and General Health Questionnaire item and total scores among $<200$ students in sample 2

\begin{tabular}{|lcc|}
\hline General Health Questionnaire item & $\begin{array}{c}\text { Correlation with Social Media } \\
\text { Disorder scale total score }(\boldsymbol{r})\end{array}$ & P Value \\
1. Lost much sleep over worry & 0.055 & 0.28 \\
\hline 2. Felt constantly under strain & 0.087 & 0.83 \\
\hline 3. Felt you could not overcome your difficulties & 0.008 & 0.87 \\
\hline 4. Been losing confidence in yourself & 0.119 & 0.02 \\
\hline 5. Been thinking of yourself as a worthless person & 0.110 & 0.03 \\
\hline 6. Feel depressed and unhappy & 0.131 & $<0.001$ \\
\hline 7. Been able to concentrate on what are doing & 0.149 & $<0.001$ \\
\hline 8. Felt you are playing a useful part & 0.158 & $<0.001$ \\
\hline 9. Been able to face up to your problems & 0.081 & 0.11 \\
\hline 10. Felt capable of making decisions & 0.159 & $<0.001$ \\
\hline 11. Been able to enjoy your day to day activities & 0.189 & $<0.001$ \\
\hline 12. Been feeling reasonably happy all things considered & 0.109 & 0.04 \\
\hline Total score & 0.170 & $<0.001$ \\
\hline
\end{tabular}


total GHQ score. This is in keeping with similar findings on associations between social media disorder and compulsive internet use, depression, and self-esteem. ${ }^{11}$

There are limitations to the present study. The age of the sample is within the upper limit of the intended population. Using only the GHQ for criterion validity in $<200$ of respondents in sample 2 is a major limitation. The lack of validated construct in Nigeria limits the wide adaptability of the criterion validity. Thus, the construct validity of the scale may not be widely applicable. Some items may be subject to high subjectivity such as the item on lying about the use of social media to parents (deception). ${ }^{11}$ Social media disorder is an evolving concept, and the cut-off score is taken from the internet gaming disorder, without prior hypothesis testing. The prevalence of social media disorder varied, depending on the age and location of respondents. More extensive studies from varied locations in Nigeria are warranted.

\section{Conclusion}

The 9-item Social Media Disorder scale is acceptable for screening social media disorder in pre-university students in Nigeria. The high prevalence of social media disorder should be of concern to counsellors, teachers, and mental health practitioners. Strategies for public health education on social media use are needed in Nigeria.

\section{Funding/support}

This research received no specific grant from any funding agency in the public, commercial, or not-for-profit sectors.

\section{Declaration}

All authors have no conflict of interest to disclose.

\section{Author contributions}

All authors had full access to the data, contributed to the study, approved the final version for publication, and take responsibility for its accuracy and integrity.

\section{References}

1. Bányai F, Zsila Á, Király O, Maraz A, Elekes Z, Griffiths $\mathrm{MD}$, et al. Problematic social media use: results from a largescale nationally representative adolescent sample. PLoS One 2017;12:e0169839. Crossref

2. Kuss DJ, Griffiths MD. Online social networking and addiction: a review of the psychological literature. Int J Environ Res Public Health 2011;8:3528-52. Crossref

3. Pew Research Center. Social Media Fact Sheet 2018. http://www. pewinternet.org/fact-sheet/social-media.

4. Lenhart A, Duggan M, Perrin A, Stepler R, Rainie L, Parker K. Teens, Social Media \& Technology Overview 2015: Smartphones Facilitate Shifts in Communication Landscape for Teens. Pew Research Center;
2015.

5. Internet World Statistics Internet Usage and Population Statistics for Africa, 2018. https://www.internetworldstats.com/africa.htm.

6. Andreassen CS, Torsheim T, Brunborg GS, PallesenS. Development of a Facebook Addiction Scale. Psychol Rep 2012;110:501-17. Crossref

7. Griffiths MD. Social networking addiction: emerging themes and issues. J Addict Res Ther 2013;4:e118. Crossref

8. Ryan T, Chester A, Reece J, Xenos S. The uses and abuses of Facebook: a review of Facebook addiction. J Behav Addict 2014;3:133-48. Crossref

9. American Psychiatric Association. Diagnostic and Statistical Manual of Mental Disorders. 5th ed. American Psychiatric Association; 2013. Crossref

10. Van Rooij AJ, Prause N. A critical review of "Internet addiction" criteria with suggestions for the future. J Behav Addict 2014;3:20313. Crossref

11. van den Eijnden RJ, Lemmens JS, Valkenburg PM. The social media disorder scale. Comput Human Behav 2016;61:478-87. Crossref

12. Andreassen CS, Billieux J, Griffiths MD, Kuss DJ, Demetrovics Z, Mazzoni E, et al. The relationship between addictive use of social media and video games and symptoms of psychiatric disorders: a large-scale cross-sectional study. Psychol Addict Behav 2016;30:25262. Crossref

13. Werneke U, Goldberg DP, Yalcin I, Üstün BT. The stability of the factor structure of the General Health Questionnaire. Psychol Med 2000;30:823-9. Crossref

14. Feyer AM, Herbison P, Williamson AM, de Silva I, Mandryk J, Hendrie L, et al. The role of physical and psychological factors in occupational low back pain: a prospective cohort study. Occup Environ Med 2000;57:116-20. Crossref

15. Goldberg DP, Gater R, Sartorius N, Ustun TB, Piccinelli M, Gureje $\mathrm{O}$, et al. The validity of two versions of the GHQ in the WHO study of mental illness in general health care. Psychol Med 1997;27:1917. Crossref

16. Pevalin DJ. Multiple applications of the GHQ-12 in a general population sample: an investigation of long-term retest effects. Soc Psychiatry Psychiatr Epidemiol 2000;35:508-12. Crossref

17. Gureje O, Obikoya B. The GHQ-12 as a screening tool in a primary care setting. Soc Psychiatry Psychiatr Epidemiol 1990;25:276-80. Crossref

18. Gureje O. Reliability and the factor structure of the Yoruba version of the 12-item General Health Questionnaire. Acta Psychiatr Scand 1991;84:125-9. Crossref

19. Tait RJ, French DJ, Hulse GK. Validity and psychometric properties of the General Health Questionnaire-12 in young Australian adolescents. Aust N Z J Psychiatry 2003;37:374-81. Crossref

20. Muthén LK, Muthén BO. Mplus User's Guide. 6th ed. Muthén \& Muthén; 2010.

21. Hu LT, Bentler PM. Cutoff criteria for fit indexes in covariance structure analysis: conventional criteria versus new alternatives. Struct Equ Modeling 1999;6:1-55. Crossref

22. Bergh D. Chi-squared test of fit and sample size: a comparison between a random sample approach and a chi-square value adjustment method. J Appl Meas 2015;16:204-17. Crossref

23. Cook KF, Kallen MA, Amtmann D. Having a fit: impact of number of items and distribution of data on traditional criteria for assessing IRT's unidimensionality assumption. Qual Life Res 2009;18:447-60. Crossref

24. MacCallum RC, Browne MW, Sugawara HM. Power analysis and determination of sample size for covariance structure modeling. Psychol Methods 1996;1:130-49. Crossref

25. Leach CW, van Zomeren M, Zebel S, Vliek ML, Pennekamp SF, Doosje B, et al. Group-level self-definition and self-investment: a hierarchical (multicomponent) model of in-group identification. J Pers Soc Psychol 2008;95:144-65. Crossref

26. Gliner JA, Morgan GA, Leech NL. Research Methods in Applied Settings: an Integrated Approach to Design and Analysis. Routledge; 2011. 